\title{
Prostate Cancer Screening in Middle-Aged and Older American Men: Combined Effects of Ethnicity and Years of Schooling
}

\author{
Shervin Assari ${ }^{*}$ \\ ${ }^{1}$ Department of Family Medicine, University of California Los Angeles, Los Angeles, CA 90095, USA \\ *Corresponding Author: Shervin Assari, M.D., M.P.H., Assistant Professor, Department of Family Medicine, University \\ of California Los Angeles, Los Angeles, CA 90095, USA. Tel: +1-323-5634800,Email: assari@umich.edu
}

Received February 6, 2020; Accepted June 1, 2020; Online Published June 11, 2020

\begin{abstract}
Background: Prostate cancer screening is more commonly utilized by highly educated people. As shown by marginalization-related diminished returns (MDRs), the effects of socioeconomic status (SES) such as education on the health outcomes are considerably smaller for ethnic minorities than for Whites. The role of MDRs as a source of ethnic health disparities is, however, still unknown. Objectives: The current study had two aims: first, to explore the association between years of schooling and having taken a prostatespecific antigen (PSA) test among men in the US, and second, to explore ethnic differences in this association.

Methods: This study was a secondary analysis of data from the National Health Interview Survey (NHIS-2015). The data of 5,053 men aged 55 years or older who were either Latino, non-Latino, African-American, or White were analyzed. Years of schooling was the independent variable. The dependent variable was taking a PSA test sometime during one's lifetime. Age, region, and employment were the control variables. Ethnicity was the focal moderating variable. Binary logistic regression was used for data analysis.

Results: A higher number of years of schooling was associated with higher odds of having taken a PSA test, net of all confounders. Ethnicity showed a significant statistical interaction with years of schooling on having taken a PSA test. This interaction was suggestive of a smaller slope for Latino men than non-Latino men. White and African American men did not show differential effects of years of schooling on having taken a PSA test.

Conclusion: Similar to the MDRs patterns in other domains, non-Latino White men show more health gain from their years of schooling than Latino men. Highly educated Latino men still need programs to encourage their use of prostate cancer screening. Keywords: Population Groups, Ethnicity, Race, Socioeconomic Status, Education, Prostate, Cancer; Screening
\end{abstract}

\section{Background}

Years of schooling and other socioeconomic status (SES) indicators have been shown to have weaker health effects for ethnic minority groups in comparison to the majority group. ${ }^{1,2}$ Also called marginalization-related diminished returns (MDRs), weaker effects of years of schooling, ${ }^{3}$ occupation, ${ }^{4}$ income, ${ }^{5}$ and marital status $^{6}$ have been shown for physical activity, ${ }^{7,8}$ drinking alcohol, ${ }^{9,10}$ cigarette smoking, ${ }^{11}$ impulse problems, ${ }^{12}$ and fruit intake ${ }^{13}$ among ethnic minorities. These MDRs have also been shown for mental health outcomes including anxiety, ${ }^{6}$ distress, ${ }^{14}$ depression, ${ }^{15}$ self-rated mental health, ${ }^{16}$ and suicide. ${ }^{17}$ Similar MDRs have also been reported for many physical health outcomes, namely obesity, ${ }^{18}$ hypertension, ${ }^{19}$ attention-deficit/hyperactivity disorder, ${ }^{20}$ asthma, ${ }^{5}$ chronic obstructive pulmonary disease, ${ }^{21}$ number of chronic diseases, ${ }^{5}$ overall health, ${ }^{16}$ disability, ${ }^{22}$ hospitalization, ${ }^{23}$ and all-cause mortality. ${ }^{24}$ These MDRs have been shown for African American, ${ }^{3}$ Latino, ${ }^{25,26}$ Asian American, ${ }^{27}$
Native American, ${ }^{28}$ and sexual minority ${ }^{29}$ individuals. This suggests any type of marginalization results in MDRs. ${ }^{30}$

Accordingly, MDRs seem to be universal, meaning that some upstream social process may systematically interfere with how resources are implemented by marginalized people. Ethnic minorities face some difficulties in translating and mobilizing their SES indicators, particularly human capital and education, to secure economic, behavioral, and health outcomes.

As a result of MDRs, high SES and educated ethnic minorities show worse than expected health outcomes. The MDRs also explain why, despite of enormous investments on closing the SES gap, ethnic health gaps have persisted over time. ${ }^{1,2,31}$ MDRs suggest that new strategies may be needed to eliminate health disparities ${ }^{1,2}$ and policy-makers should go beyond equalizing SES to eliminate health inequalities across ethnic groups. ${ }^{1,2}$ MDRs also provide evidence that policies should invest in changing the existing social stratification system that is continuously generating

Copyright (C 2020 The Author(s). This is an open-access article distributed under the terms of the Creative Commons Attribution License (http:// creativecommons.org/licenses/by/4.0), which permits unrestricted use, distribution, and reproduction in any medium, provided the original work is properly cited. 
deep inequalities at all SES levels. ${ }^{1,2}$ With MDRs in mind, health inequalities should not be seen as a problem merely in low SES individuals, but as an issue that also generates disparities in the middle class. ${ }^{1,2}$

While several studies have established the existing MDRs for the effects of SES indicators such as years of schooling on several health behaviors, ${ }^{8,9,11,13,25,32}$ very few studies have tested MDRs for preventive health service utilization. ${ }^{33-35}$ Some recent studies have suggested that health behaviors such as healthcare professional visitation and screening care may also be influenced by MDRs. ${ }^{35,36}$ Only four studies were found to have shown the effects of MDRs of years of schooling and SES on health service use. The first one documented MDRs of years of schooling on preventive dental visits ${ }^{35}$; the second study showed MDRs of age on having a patient-doctor conversation about lung cancer screening ${ }^{36}$; and the third study showed MDRs of years of schooling on breast cancer screening. ${ }^{34}$ None of these studies, however, established MDRs of years of schooling on having taken a PSA test among men. As such, there is a need to determine whether the number of years of education similarly increases the odds of prostate cancer screening.

\section{Objectives}

To investigate the MDRs of years of schooling on prostatespecific antigen (PSA)-based screening of prostate cancer among African American and Latino men, a comparison was made of non-Latino and Latino White and African American men for the link between years of schooling and lifetime PSA test utilization. Being informed by the theory of MDRs, ${ }^{1,2}$ it was hypothesized that there would be weaker associations between years of schooling and PSA test utilization for African American and Latino men in comparison to non-Latino White men. In other words, it was expected that a larger proportion of highly educated African American and Latino men would report never having taken a PSA test compared to highly educated nonLatino White men.

\section{Methods}

The National Health Interview Survey (NHIS 2015) is a national health survey of American adults performed by the National Center for Health Statistics (NCHS), which is a section of the Centers for Disease Control and Prevention (CDC). Data was collected through face-to-face interviews conducted in the participants' homes. For a proportion of participants, face-to-face interviews were followed by a telephone interview.

\subsection{Participants and Sampling}

The NHIS samples were US residents, noninstitutionalized, civilians, and adults. To enroll the sample for the NHIS, a multi-stage sampling strategy was applied.

\subsection{The Analytical Sample}

A total number of 5,053 adult middle-aged and older men were included in this analysis. This included all men who participated in the NHIS, were 55+ years old, were nonLatino or Latino White or African American, and had valid data on having or not having had a PSA test in their lifetime. The study was restricted to males above 55 years old, because the PSA test is not relevant to women, and this research focused on middle-aged and older adults.

\subsection{Measures}

\subsubsection{Moderator}

Ethnicity. Ethnicity was self-reported and treated as two dichotomous variables: African Americans $=1$, Whites $=0$ (reference category), and Non-Latino $=0$ (reference category), Latino $=1$.

\subsubsection{Predictor}

Years of schooling (EA). Years of schooling, treated as a continuous measure, was the independent/predictor variable. Years of schooling ranged between 0 and 21, with a higher score reflecting a higher number of years of schooling.

\subsubsection{Dependent Variable}

PSA. Participants were asked if they had ever taken a PSA test. The answers, either yes or no, were treated as a dichotomous variable: $0=$ PSA-, $1=$ PSA + .

\subsubsection{Covariates}

Demographic Characteristics. Demographic data in the current study included age, employment status, and region of domicile. Age was an interval variable. Region, a categorical variable, included the Northeast, Midwest, South, or West. Employment was a dichotomous variable coded 1 for employed and 0 for other statuses.

\subsection{Statistics}

Because the NHIS used a multi-stage sampling design, adjustments needed to be made for the survey weights. To describe the sample, weighted means and frequencies were used. To perform multivariable analyses, two logistic regression models were applied in the overall sample. In all models, number of years of schooling was the independent variable, PSA was the outcome / dependent variable, and ethnicity was the moderating variable (moderator). The first two models were performed in the pooled sample. Model 1 did not enter ethnicity by years of schooling interaction terms, but Model 2 did. All analyses were performed in SPSS 23 (IBM Inc., New York, U.S.).

\section{Results}

This study included 5,053 men who were either White (87.2\%), African American (12.8\%), Latino (7.3\%), or non-Latino (92.7\%). Table 1 describes the participating men for various variables. From all men, 33.5\% had never done a PSA exam. The remaining $66.5 \%$ had taken a PSA test at least once in their lifetime (Table 1). 
Table 1. Descriptive Statistics of Participating Men $(n=5053)$

\begin{tabular}{|c|c|c|}
\hline Characteristics & Mean & SE \\
\hline Age (y) & 67.68 & 8.73 \\
\hline \multirow[t]{2}{*}{ Education (y) } & 15.05 & 3.43 \\
\hline & $\mathbf{n}$ & $\%$ \\
\hline \multicolumn{3}{|l|}{ Race } \\
\hline White & 4408 & 87.2 \\
\hline African American & 645 & 12.8 \\
\hline \multicolumn{3}{|l|}{ Ethnicity } \\
\hline Non-Latino & 4685 & 92.7 \\
\hline Latino & 368 & 7.3 \\
\hline \multicolumn{3}{|l|}{ Region } \\
\hline Northeast & 891 & 17.6 \\
\hline Midwest & 1128 & 22.3 \\
\hline South & 1743 & 34.5 \\
\hline West & 1291 & 25.5 \\
\hline \multicolumn{3}{|l|}{ Employment } \\
\hline No & 3294 & 65.2 \\
\hline Yes & 1759 & 34.8 \\
\hline \multicolumn{3}{|l|}{ PSA } \\
\hline No & 1695 & 33.5 \\
\hline Yes & 3358 & 66.5 \\
\hline
\end{tabular}

PSA, prostate-specific antigen.

Two logistic regression models are summarized in Table 2. Based on Model 1 (the main effect model), high years of schooling was correlated with higher odds of having taken a PSA test, net of all study confounders. Model 2 (the interaction term model) showed a negative interaction term between Latino ethnicity and years of schooling. This interaction documented a smaller effect of years of schooling on the odds of having a PSA test for Latino than non-Latino men. The same interaction could not be found between African American men and years of schooling, suggesting a similar effect of years of schooling on having a PSA test for African American and White men (Table 2).

\section{Discussion}

This study showed a weaker effect of education (years of schooling) on having taken a PSA test in Latino than non-Latino men. No variation was found in the effects of education on having taken a PSA test between African American and White men.

MDRs of years of schooling could be documented on Latino but not African American men's usage of PSA tests. The findings regarding Latino men are in line with the literature. ${ }^{1,2}$ In the US, education is not "the great equalizer." ${ }^{37,38}$ Several studies by Anna Zajacova ${ }^{37,38}$ and other investigators such as Hayward and Montez ${ }^{39-41}$ have documented racial differences in the protective effects of education on mortality. This research has shown that both years of schooling and educational credentials better promote the health of non-Latino Whites than African Americans.

Our observations in Latino men support the growing literature on MDRs. Various studies have shown that SES and social determinants of health have smaller effects on ethnic minorities than on non-Latino Whites. These patterns have been shown for various mental health outcomes such as happiness, ${ }^{42}$ depression, ${ }^{15}$ impulsivity, ${ }^{12}$ and suicide. ${ }^{17}$ They have also been shown for behaviors such as cigarette smoking, ${ }^{11}$ alcohol drinking, ${ }^{9,10}$ fruit and vegetable intake, ${ }^{13}$ exercise, ${ }^{8}$ and sleep. ${ }^{7}$ Years of schooling and other SES resources better reduce obesity, ${ }^{18}$ chronic disease, ${ }^{5}$ and overall health ${ }^{16}$ for Whites than for ethnic minorities; however, this line of work focused mainly on the comparison of Whites and African Americans.

Weaker than expected effects of educational level on increasing pro-health behaviors of ethnic minority men may be due to differential quality of education across ethnic groups. Latinos tend to attend urban and inner-

Table 2. Logistic Regression on the Link Between Years of Schooling and Having Taken a PSA Test in the Pooled Sample of American Men

\begin{tabular}{|c|c|c|c|c|c|c|}
\hline \multirow{2}{*}{ Characteristics } & \multicolumn{3}{|c|}{ Model 1} & \multicolumn{3}{|c|}{ Model 2} \\
\hline & OR & $95 \% \mathrm{Cl}$ & $P$ value & OR & $95 \% \mathrm{Cl}$ & $P$ value \\
\hline Race (African Americans) & 0.84 & $0.69-1.01$ & 0.058 & 1.30 & $0.62-2.74$ & 0.486 \\
\hline Ethnicity (Latinos) & 0.60 & $0.48-0.76$ & 0.000 & 1.23 & $0.62-2.44$ & 0.547 \\
\hline \multicolumn{7}{|l|}{ Region } \\
\hline West & 1.00 & & & 1.00 & & \\
\hline Northeast & 0.97 & $0.80-1.17$ & 0.749 & 0.97 & $0.81-1.18$ & 0.779 \\
\hline Midwest & 1.12 & $0.94-1.34$ & 0.200 & 1.13 & $0.95-1.36$ & 0.169 \\
\hline South & 1.24 & $1.05-1.46$ & 0.010 & 1.25 & $1.06-1.47$ & 0.008 \\
\hline Age & 1.06 & $1.05-1.07$ & 0.000 & 1.06 & $1.05-1.07$ & 0.000 \\
\hline Employed & 1.03 & $0.89-1.19$ & 0.682 & 1.03 & $0.89-1.19$ & 0.710 \\
\hline Education (Years) & 1.15 & $1.12-1.17$ & 0.000 & 1.16 & $1.14-1.19$ & 0.000 \\
\hline Education (Years) $\times$ Race (African Americans) & & & & 0.97 & $0.92-1.02$ & 0.240 \\
\hline Education (Years) $\times$ Ethnicity (Latinos) & & & & 0.95 & $0.90-1.00$ & 0.031 \\
\hline Intercept & 0.01 & & 0.000 & 0.01 & & 0.000 \\
\hline
\end{tabular}


city schools with scarce educational resources. This is, in part, because of segregation that reduces the health return of schooling for non-Whites. Given the lower quality of education, each additional year of education has a weaker effect on building human capital and healthy behaviors for ethnic minority people. On top of unequal education, the effects of education may be reduced because of labor market preferences and practices. Due to discrimination in the labor market, highly educated minorities work in worse occupations that generate less income and wealth, which are required for a healthy lifestyle. As a result, highly educated ethnic minorities get a lower chance to translate their education into tangible outcomes. ${ }^{42,43}$ Interpersonal discrimination also minimizes the health gains that are commonly seen as a result of a high education level. ${ }^{3,11,14,29,35,44,45}$

Due to racism, social stratification, residential segregation, and discrimination, ethnic minority groups are more likely to remain poor despite education. ${ }^{43}$ Highly educated ethnic minority people remain at risk of living in low-income, unsafe, resource-scarce areas. ${ }^{18,46}$ Highly educated ethnic minorities are also exposed to higher levels of stress and more environmental toxins. ${ }^{47-49}$ Finally, highly educated ethnic minorities work in worse jobs with lower pay and higher stress. ${ }^{50}$ This also applies to high SES ethnic minorities, such as Latino and African Americans who still live in majority Latino or in high stress low resource neighborhoods where health-seeking or preventative care is not the main priority. ${ }^{51-55}$ Access to clinics and health services As well as public transportation is also limited. ${ }^{56}$ Thus, even for people who are motivated to seek care, their environment operates as a barrier that promotes an unhealthy lifestyle. People in these high risk communities face crime and violence that also act as a barrier against living a healthy lifestyle..$^{51-55}$ Thus, relative to high SES non-Latino Whites, high SES ethnic minorities may not similarly follow pro-health behaviors. Future research is needed on contextual constraints that generate gaps in health behaviors of high SES non-Latino Whites, African Americans, and Latinos. ${ }^{18}$

\subsection{Limitations}

The current study was limited by a cross-sectional design, unmeasured confounders, measurement bias, and its scope which was restricted to African Americans, Latinos, and non-Latino Whites. Cross-sectional studies show associations, not causal effects. Moreover, not all confounders were controlled. Other SES indicators such as income and wealth were omitted from this study. In addition, the study did not control for access or medical needs. Access to public transportation, distance to health care facilities, medical mistrust, having insurance, and other similar indicators of access to medical care/medical needs were not measured. Other confounding variables such as having other types of cancer and family history were not considered in this study. The outcomes were measured using a single self-reported item. The timing of

\section{Research Highlights}

\section{What Is Already Known?}

The number of years of schooling (education) increases pro-health behaviors and health utilization such as cancer screening.

\section{What This Study Adds?}

Education shows a weaker effect on increasing the chance of prostate cancer screening in Latino than non-Latino men. As a result, middle class and highly educated Latino men remain without PSA-based prostate cancer screening.

when a PSA test was taken was not measured. It is likely that race, education, and their interaction would not only change lifetime PSA test usage, but also the timing of the test itself. Future research may consider the length of time since the most recent PSA test as well as cases of delayed PSA testing. These types of information would explain how race and SES cause delays in taking a PSA test. This item could be validated by triangulation methods and chart review or claim data. Finally, it is not known if the same pattern can be seen for Asian Americans, Native Americans, immigrants, or LGBT men. Latino men vary based on culture, SES, country of origin, nativity, immigration status, and language. ${ }^{7,57-61}$ Future studies should compare various sub-groups of Latino men.

\section{Conclusion}

Ethnicity changes the effect years of schooling has on having taken a PSA test for American men. In this study, years of schooling better enhanced non-Latino men's chance of having taken a PSA exam rather than Latino men's chance, although the same pattern was not observed when White and African American men were compared. MDRs must be reduced if health disparities in prostate cancer screening due to ethnicity are to be reduced.

\section{Conflict of Interest Disclosures}

The author declares that he has no conflicts of interest.

\section{Ethical Approval}

This study has used publicly available data which were fully de-identified. Thus, it was non-human subject research.

\section{Funding/Support}

SA is supported by the National Institutes of Health (NIH) grants CA201415-02, 5S21MD000103, D08452603, CA201415-02, DA035811-05, U54MD008149, U54MD007598, U54CA229974, and U54CA229974.

\section{References}

1. Assari S. Health disparities due to diminished return among black Americans: public policy solutions. Soc Issues Policy 
Rev. 2018;12(1):112-145. doi:10.1111/sipr.12042.

2. Assari S. Unequal gain of equal resources across racial groups. Int J Health Policy Manag. 2018;7(1):1-9. doi:10.15171/ ijhpm.2017.90.

3. Assari S. Parental educational attainment and mental wellbeing of college students; diminished returns of Blacks. Brain Sci. 2018;8(11). doi:10.3390/brainsci8110193.

4. Assari S. Life expectancy gain due to employment status depends on race, gender, education, and their intersections. J Racial Ethn Health Disparities. 2018;5(2):375-386. doi:10.1007/s40615-017-0381-x.

5. Assari S, Moghani Lankarani M. Poverty status and childhood asthma in white and black families: National Survey of Children's Health. Healthcare (Basel). 2018;6(2). doi:10.3390/ healthcare6020062.

6. Assari S, Caldwell CH, Zimmerman MA. Family structure and subsequent anxiety symptoms; minorities' diminished return. Brain Sci. 2018;8(6). doi:10.3390/brainsci8060097.

7. Assari S, Nikahd A, Malekahmadi MR, Moghani Lankarani $M$, Zamanian $H$. Race by gender group differences in the protective effects of socioeconomic factors against sustained health problems across five domains. J Racial Ethn Health Disparities. 2016. doi:10.1007/s40615-016-0291-3.

8. Assari S. Educational attainment and exercise frequency in American women; blacks' diminished returns. Womens Health Bull. 2019;6(3). doi:10.5812/whb.87413.

9. Assari S, Farokhnia M, Mistry R. Education attainment and alcohol binge drinking: diminished returns of Hispanics in Los Angeles. Behav Sci (Basel). 2019;9(1). doi:10.3390/bs9010009.

10. Assari S, Moghani Lankarani M. Education and alcohol consumption among older Americans; black-white differences. Front Public Health. 2016;4:67. doi:10.3389/ fpubh.2016.00067.

11. Assari S, Mistry R. Educational attainment and smoking status in a national sample of American adults; evidence for the blacks' diminished return. Int J Environ Res Public Health. 2018;15(4). doi:10.3390/ijerph15040763.

12. Assari S, Caldwell CH, Mincy R. Family socioeconomic status at birth and youth impulsivity at age 15; blacks' diminished return. Children(Basel).2018;5(5).doi:10.3390/children5050058.

13. Assari S, Moghani Lankarani M. Educational attainment promotes fruit and vegetable intake for whites but not Blacks. J (Basel). 2018;1(1):29-41. doi:10.3390/j1010005.

14. Assari S. Educational attainment better protects African American women than African American men against depressive symptoms and psychological distress. Brain Sci. 2018;8(10). doi:10.3390/brainsci8100182.

15. Assari S. High income protects whites but not African Americans against risk of depression. Healthcare (Basel). 2018;6(2). doi:10.3390/healthcare6020037.

16. Assari S, Lapeyrouse LM, Neighbors HW. Income and selfrated mental health: diminished returns for high income black Americans. Behav Sci (Basel). 2018;8(5). doi:10.3390/ bs8050050.

17. Assari S. Ethnic and gender differences in additive effects of socio-economics, psychiatric disorders, and subjective religiosity on suicidal ideation among blacks. Int J Prev Med. 2015;6:53. doi:10.4103/2008-7802.158913.

18. Assari S. Family income reduces risk of obesity for white but not black children. Children (Basel). 2018;5(6). doi:10.3390/ children5060073.

19. Assari S. Socioeconomic determinants of systolic blood pressure; minorities' diminished returns. J Health Econ Dev. 2019;1(1):1-11.

20. Assari S, Caldwell CH. Family income at birth and risk of attention deficit hyperactivity disorder at age 15: racial differences. Children (Basel). 2019;6(1). doi:10.3390/ children6010010

21. Assari S CH, Bazargan M. Educational Attainment Unequally Delays Smoking Initiation for Non-Hispanic Black and NonHispanic White Americans. International Journal of Biomedical Engineering and Clinical Science. 2019

22. Assari S, Bazargan M. Educational attainment better reduces disability for non-Hispanic than Hispanic Americans. Eur J Investig Health Psychol Educ. 2020;10(1):10-17. doi:10.3390/ ejihpe10010002.

23. Assari S, Bazargan M. Minorities' diminished returns of educational attainment on hospitalization risk: National Health Interview Survey (NHIS). Hosp Pract Res. 2019;4(3):86-91. doi:10.15171/hpr.2019.17.

24. Assari S, Moghani Lankarani M. Race and urbanity alter the protective effect of education but not income on mortality. Fron Public Health. 2016;4:100. doi:10.3389/fpubh.2016.00100.

25. Assari S, Mistry R. Diminished return of employment on ever smoking among Hispanic whites in Los Angeles. Health Equity. 2019;3(1):138-144. doi:10.1089/heq.2018.0070.

26. Assari S. Socioeconomic status and self-rated oral health; diminished return among Hispanic whites. Dent J (Basel). 2018;6(2). doi:10.3390/dj6020011.

27. Assari S. Diminished returns of income against cigarette smoking among Chinese Americans. J Health Econ Dev. 2019;1(2):1-8

28. Assari S, Bazargan M. Protective effects of educational attainment against cigarette smoking; diminished returns of American Indians and Alaska natives in the National Health Interview Survey. Int J Travel Med Glob Health. 2019;7(3):105110. doi:10.15171/ijtmgh.2019.22.

29. Assari S. Education attainment and obesity: differential returns based on sexual orientation. Behav Sci (Basel). 2019;9(2). doi:10.3390/bs9020016.

30. Assari S. Unequal gain of equal resources across racial groups. Int J Health Policy Manag. 2018;7(1):1-9. doi:10.15171/ ijhpm.2017.90.

31. Assari S. Blacks' diminished return of education attainment on subjective health; mediating effect of income. Brain Sci. 2018;8(9). doi:10.3390/brainsci8090176.

32. Assari S, Mistry R, Bazargan M. Race, educational attainment, and e-cigarette use. J Med Res Innov. 2020;4(1). doi:10.32892/ jmri.185

33. Chance of Breast Physical Exam for Non-Hispanic Than Hispanic American Women: National Health Interview Survey. Hosp Pract Res. 2019;4(4):122-127. doi:10.15171/ hpr.2019.25.

34. Assari S, Bazargan M. Educational attainment better increases the chance of breast physical exam for non-Hispanic than Hispanic American women: National Health Interview Survey. Hosp Pract Res. 2019;4(4):122-127. doi:10.15171/ hpr.2019.25.

35. Assari S, Hani N. Household income and children's unmet dental care need; blacks' diminished return. Dent J (Basel) 2018;6(2). doi:10.3390/dj6020017.

36. Chalian H, Khoshpouri P, Assari S. Patients' age and discussion with doctors about lung cancer screening; diminished returns of Blacks. Aging Med (Milton). 2019;2(1):35-41. doi:10.1002/ agm2.12053.

37. Zajacova A, Johnson-Lawrence V. Anomaly in the educationhealth gradient: biomarker profiles among adults with subbaccalaureate attainment levels. SSM Popul Health 2016;2:360-364. doi:10.1016/j.ssmph.2016.05.001.

38. Zajacova A, Rogers RG, Johnson-Lawrence V. Glitch in the gradient: additional education does not uniformly equal better health. Soc Sci Med. 2012;75(11):2007-2012. doi:10.1016/j. socscimed.2012.07.036

39. Montez JK, Hummer RA, Hayward MD, Woo H, Rogers RG 
Trends in the educational gradient of US adult mortality from 1986 through 2006 by race, gender, and age group. Res Aging. 2011;33(2):145-171. doi:10.1177/0164027510392388.

40. Brown DC, Hayward MD, Montez JK, Hummer RA, Chiu CT, Hidajat MM. The significance of education for mortality compression in the United States. Demography. 2012;49(3):819-840. doi:10.1007/s13524-012-0104-1.

41. Montez JK, Zajacova A, Hayward MD, Woolf SH, Chapman D, Beckfield J. Educational disparities in adult mortality across US states: how do they differ, and have they changed since the mid-1980s? Demography. 2019;56(2):621-644. doi:10.1007/ s13524-018-0750-z.

42. Assari S, Preiser B, Kelly M. Education and income predict future emotional well-being of whites but not Blacks: a ten-year cohort. Brain Sci. 2018;8(7). doi:10.3390/brainsci8070122.

43. Assari S. Parental education better helps white than black families escape poverty: National Survey of Children's Health. Economies. 2018;6(2):30.

44. Assari S. Parental education attainment and educational upward mobility; role of race and gender. Behav Sci (Basel). 2018;8(11). doi:10.3390/bs8110107.

45. Assari S, Moghani Lankarani M. Workplace racial composition explains high perceived discrimination of high socioeconomic status African American men. Brain Sci. 2018;8(8). doi:10.3390/ brainsci8080139.

46. Assari S, Thomas A, Caldwell CH, Mincy RB. Blacks' diminished health return of family structure and socioeconomic status; 15 years of follow-up of a national urban sample of youth. J Urban Health. 2018;95(1):21-35. doi:10.1007/s11524-0170217-3.

47. Assari S, Bazargan M. Unequal effects of educational attainment on workplace exposure to second-hand smoke by race and ethnicity; minorities' diminished returns in the National Health Interview Survey (NHIS). J Med Res Innov. 2019;3(2):e000179. doi:10.32892/jmri.179.

48. Assari S, Boyce S, Bazargan M, Caldwell CH. A dream deferred: African American women's diminished socioeconomic returns of postponing childbearing from teenage to adulthood. Reprod Med. 2020;1:62-76. doi:10.3390/reprodmed1020005.

49. Assari S, Bazargan M. Second-hand smoke exposure at home in the United States; minorities' diminished returns. Int J Travel Med Glob Health. 2019;7(4):135-141. doi:10.15171/ ijtmgh.2019.28.

50. Assari S, Bazargan M. Unequal associations between educational attainment and occupational stress across racial and ethnic groups. Int J Environ Res Public Health. 2019;16(19). doi:10.3390/ijerph16193539.
51. Malambo P, De Villiers A, Lambert EV, Puoane T, Kengne AP. Associations of perceived neighbourhood safety from traffic and crime with overweight/obesity among South African adults of low-socioeconomic status. PLoS One. 2018;13(10):e0206408. doi:10.1371/journal.pone.0206408.

52. Assari S, Moghani Lankarani $\mathrm{M}$, Caldwell $\mathrm{CH}$, Zimmerman MA. Fear of neighborhood violence during adolescence predicts development of obesity a decade later: gender differences among African Americans. Arch Trauma Res. 2016;5(2):e31475. doi:10.5812/atr.31475.

53. Choi SW, Park DJ, Kim J, et al. Association between obesity and neighborhood socioeconomic status in Korean adolescents based on the 2013 Korea youth risk behavior web-based survey. Korean J Fam Med. 2016;37(1):64-70. doi:10.4082/ kjfm.2016.37.1.64.

54. Li F, Harmer P, Cardinal BJ, Bosworth M, Johnson-Shelton D. Obesity and the built environment: does the density of neighborhood fast-food outlets matter? Am J Health Promot. 2009;23(3):203-209. doi:10.4278/ajhp.071214133.

55. Kwate NO. Fried chicken and fresh apples: racial segregation as a fundamental cause of fast food density in black neighborhoods. Health Place. 2008;14(1):32-44. doi:10.1016/j. healthplace.2007.04.001.

56. Sharkey JR, Horel S. Neighborhood socioeconomic deprivation and minority composition are associated with better potential spatial access to the ground-truthed food environment in a large rural area. J Nutr. 2008;138(3):620-627. doi:10.1093/ jn/138.3.620.

57. Assari S. Psychosocial correlates of body mass index in the United States: intersection of race, gender and age. Iran J Psychiatry Behav Sci. 2016;10(2):e3458. doi:10.17795/ ijpbs-3458.

58. Carter JD, Assari S. Sustained obesity and depressive symptoms over 6 years: race by gender differences in the health and retirement study. Front Aging Neurosci. 2016;8:312. doi:10.3389/fnagi.2016.00312.

59. Assari S, Moghani Lankarani M. Mediating effect of perceived overweight on the association between actual obesity and intention for weight control; role of race, ethnicity, and gender. Int J Prev Med. 2015:6:102. doi:10.4103/2008-7802.167616.

60. Assari S, Moghani Lankarani M. The association between obesity and weight loss intention weaker among Blacks and men than Whites and women. J Racial Ethn Health Disparities. 2015;2(3):414-420. doi:10.1007/s40615-015-0115-x.

61. Assari S. Additive effects of anxiety and depression on body mass index among Blacks: role of ethnicity and gender. Int Cardiovasc Res J. 2014;8(2):44-51. 